DOI 10.37882/2223-2982.2020.09-2.05

\title{
НАЦИОНАЛЬНО-КУЛЬТУРНАЯ СЕМАНТИКА РУССКИХ РЕАЛИЙ В ЗЕРКАЛЕ БРАЗИЛЬСКОЙ КУЛЬТУРЫ (НА МАТЕРИАЛЕ ПЕРЕВОДА ДАРИО МОРЕЙРА КАСТРО АЛВЕСА НА ПОРТУГАЛЬСКИЙ ЯЗЫК)
}

\section{NATIONAL AND CULTURAL SEMANTICS \\ OF RUSSIAN REALIA IN THE MIRROR \\ OF BRAZILIAN CULTURE (BASED ON \\ THE TRANSLATION OF DARIO MOREIRA CASTRO ALVES INTO PORTUGUESE) \\ V. Danilova}

Summary: Comparative linguistic and regional studies, which arose at the connection of language and culture, explores the non-coinciding (national) elements of both languages and both cultures, where the complex of coinciding and diverging units, as practice shows, will be different, although self-knowledge of reality, obviously, has a universal human character without any national restrictions. The subject of comparative linguistic and cultural research in our work is the realia of the Russian language and the lexemes that translate these realia into the Portuguese translation of the novel «Eugene Onegin». The purpose of our study is to identify the mismatched national and cultural elements of both languages and both cultures, which demonstrate differences in understanding and interpretation of culturally significant information by native speakers of Russian and Portuguese. Our main task is to study and describe the distinctive features of the expression of cognitive-semantic information in linguistic pictures or images of the world at the level of lexical-semantic relations.

Keywords: realia, linguistic and regional studies, comparative analysis, national-cultural semantics, Portuguese language.

\author{
Данилова Василиса Андреевна \\ Аспирант, Московский государственный \\ университет им. М.В. Ломоносова \\ vasilisa.danilovatpp@mail.ru
}

Аннотация: Сопоставительное лингвострановедение, возникшее на стыке языка и культуры исследует несовпадающие (национальные) элементы обоих языков и обеих культур, где совокупности совпадающих и расходящихся единиц, как показывает практика, будут различными, хотя самопознание действительности, очевидно, имеет общечеловеческий характер без какихлибо национальных ограничений. Предметом сопоставительного лингвострановедческого исследования в нашей работе являются реалии русского языка и лексемы транслирующие эти реалии в португальском переводе романа «Евгений Онегин». Целью нашего исследования является выявление несовпадающих национально-культурных элементов обоих языков и обеих культур, которые демонстрируют различия понимания и интерпретации культурно значимой информации носителями русского и португальского языков. Основной задачей мы ставим изучение и описание отличительных особенностей выражения когнитивно-семантической информации в языковых картинах или образах мира на уровне лексико-смысловых отношений.

Ключевые слова: реалии, лингвострановедение, сопоставительный анализ, национально-культурная семантика, португальский язык.

с другой и осознание единства различий этих языковых культур» [2, с. 27]. Структура национальной личности определяется на когнитивном уровне со всеми ассоциативными связями, входящими в лексическое значение. Связь «ближайшего и дальнейшего значений» [3, с. 19] реалий выступает условием актуализации когнитивной значимости, которая может и должна быть, по нашему мнению, сопоставима с лингвострановедческим понятием «фоновые семантические доли» [4 с, 297] в условиях межъязыковой и межкультурной коммуникации. Под реалиями мы понимаем культурно-маркированные слова, характерные для определенной языковой общности, и отсутствующие в другой. Культурные компоненты значения данных слов в лингвострановедении называют фоновыми семантическими долями [5, с. 38]. Фоновые семантические доли составляют структуру значения слова, 
более того, их роль возрастает в процессе актуализации когнитивной значимости при изучении иностранного языка. Актуализация смыслового содержания реалий определяется когнитивной значимостью, восприятие которой обусловлено принадлежностью реципиента к определенной национальной (локальной) культуре.

Культурный компонент значения лексем (или национально-культурные семантические доли в терминах сопоставительного лингвострановедения) может входить в лексическое понятие (денотат), и такое слово рассматривается как возникшее внутри данной исторической общности людей, а также может присутствовать на уровне лексического фона (коннотации). В этих случаях понятийно тождественные лексические единицы обладают расхождениями в области семантической периферии, т.е. знаний и ассоциаций, сопряженных с данным предметом или явлением в сознании носителей данного языка [6, с. 110]. В этой связи в данном исследовании мы будем рассматривать как денотативные, так и коннотативные реалии. При лингвострановедческой семантизации слов-реалий, как денотативных, так и коннотативных, необходимо обращать внимание на культурно-исторический фон слова и социально-историческое наполнение его содержания. В характеристике структуры внутрисловной парадигмы русских культурномаркированных слов и их португальских соответствий в переводе (с учетом экстралингвистических факторов, влияющих на формирование национально-культурной семантики слов) мы выделим три этапа:

1. Формирование контрастивных пар, состоящих из слов-реалий русского языка и их португальских переводческих соответствий.

2. Выявление национально-культурных компонентов значения сопоставляемых лексем, что предполагает описание следующих блоков информации:

- Количественная характеристика парадигм (лексико-семантические значения языковых единиц в сопоставляемых языках);

- Сведения о мотивационных признаках лексем;

- Характеристика сочетаемостной возможности слова и социально-культурного наполнения содержания этих словосочетаний;

- Сведения о коннотации: эмоциональной и эмотивной оценках, стилистической окраске лексем;

- Сведения о фоновых значениях лексем: социокультурные сведения, культурные коннотации и ассоциации характерные лишь для определенной нации или национальности, освоенные массой их представителей и отраженные в языке; данной национальной общности

3. Сопоставление национально-культурных компонентов значения лексем русского и португальского языков и выявление несовпадающих компонентов значения слов в двух языка.
Проводя этот вид анализа, мы полагаемся на данные толковых словарей, в которых имеется перечень значений слов и толкование их содержания [7], [8].

Языковые реалии в романе «Евгений Онегин» отражают особенности уклада жизни русского народа в XIX веке. Сопоставляя реалии русского языка и их португальские соответствия в переводе, возможно исследовать особенности восприятия русской жизни носителями португальского языка и выявить национальнокультурные различия языковых картин мира носителей двух языков.

В результате выборочного сопоставления словреалий двух языков мы установили некоторые группы слов по признакам их различия. Наиболее важными, как нам кажется, являются 4 группы сопоставляемых единиц.

1. Реалии, присущие только одной культуре и обладающие ярким национально-культурным содержанием (P1, K1;P2, K2).

Сюда можно отнести реалии, тесно связанные с традиционным бытом народа, его историей, географией и фольклором. В них как в зеркале отражается специфика национальной культуры. Для русских такими реалиями являются слова, обозначающие: традиционные блюда и напитки. Например, щи в сознании русских ассоциируются с благополучием, что находит отражение в фольклоре: «щей горшок да сам большой». Щи представляли большую ценность для русского человека: «Щи да каша — мать (жизнь) наша» ; «Отец родной надоест, а щи не надоедят!».

Историческую память о квасе как основной пище бедных людей сохранило выражение «с хлеба на квас перебиваться», то есть жить плохо, бедно, терпеть нужду. Квасным патриотизмом называют огульное восхваление всего своего, русского, даже самых отсталых форм жизни и быта, и порицание всего чужого.

К реалиям, не имеющим аналогов в другой культуре, можно отнести слова, обозначающие народные танцы и музыкальные инструменты.

Например, в русском языке балалайка в переносном значении ассоциируется с болтливостью и входит в состав устойчивого выражения «бесструнная балалайка». Бесструнной балалайкой называют болтливого человека.

Народный русский танец трепак исполняется в очень быстром темпе. С этим связано возникновение фразеологизма «дать трепака» - быстро бежать.

Реалиями, которые не имеют аналогов в других куль- 
турах, но при этом обладают ярко выраженным культурным содержанием, можно назвать некоторые старинные русские меры измерения, например, аршин. Разница в длине аршинов стала причиной появления выражения «мерить на свой аршин», то есть судить о чем-нибудь из корыстных соображений односторонне, субъективно. Это значение слова в современном русском языке сохранилось и во фразеологизме как «(словно, будто) аршин проглотил». Так говорят о человеке, который держится неестественно прямо и скованно.

Слова, обозначающие некоторые старинные виды транспорта, являются культурно-маркированными и не имеют аналогов в других языках. Например, с тройкой в русской культуре ассоциируется образ дороги, простора, свободы. Благодаря произведению Н.В. Гоголя «Мертвые души» тройка стала один из символов Родины.

Отметим, что для бразильцев такими реалиями с ярко выраженным национально-культурным содержанием могут быть слова, обозначающие национальные блюда и напитки, например: feijoada, tapioca, cachaça, caipirinha; народные танцы и инструменты: pandeiro, berimbau, frevo, fandango; мифологические и фольклорные персонажи: Cuca, Papa-figo, Besta Fera и многие другие.

2. Реалии, обозначающие тождественные и схожие понятия, но обладающие национально-культурным содержанием только в одной культуре (P1 = P2, К1 или K2) .

Чаще всего в качестве символов выступают предметы, имеющиеся в двух культурах, но символика, представленная в культуре одного народа, может отсутствовать в культуре другого.

Например, в русской культуре слово береза, ничего не говорящее бразильцем, коннотативно окрашено. В русском фольклоре берёза олицетворяет женское начало, символизирует красоту, стройность и чистоту девушки, и в широком смысле считается одним из символов России.

Рябина в русской фольклорной традиции ассоциируется с женским одиночеством, а ее горькие ягоды - с горькой женской долей и является олицетворением женского начала (так же, как береза). В русской поэзии рябина - один из символов Родины.

В Бразилии дуб понимается исключительно как вид дерева, распространенный в европейской части России, а в русском культурном узусе дуб олицетворяет мужское начало, долголетие, силу, стойкость, мужество.

Лuna и способы ее обработки метафорически отразились в русском языке и не понимаются носителями пор- тугальского языка. В сознании русских людей обдирание липового лыка ассоциируется с отбиранием всего, ограблением - «ободрать как липку». В переносном значении липой называются подделку или фальшивку.

Некоторые слова обозначают понятия, которые имеют аналоги в бразильской культуре, однако в отличие от русских слов не обладают национально-культурным содержанием.

Одним из распространенных лакомств в России является пряник. В Бразилии можно увидеть аналог пряника — pão de mel (медовый хлеб), однако в португальском языке ра̃o de mel не имеет культурных коннотаций, в то время как в сознании русских людей пряник вызывает ряд ассоциациативных образов. Например, пряник ассоциируется с поощрением: слово пряник входит в состав выражения «политика кнута и пряника», означающего линию поведения, основанную на смене поощрений и наказаний. Пряником в переносном значении в разговорной речи называют слабохарактерного, безынициативного человека.

Кафтан был очень распространенной одеждой в Древней Руси, что не могло не отразиться в русской культуре и языке. Например, по типу кафтана можно было определить вид деятельности и принадлежность человека к тому или иному сословию или роду деятельности. Кафтан воспринимался русскими как показатель достатка. В португальском языке есть слово cafetã, которое обозначает схожее понятие, но не имеет культурных коннотаций и ассоциаций.

В русском культуре лапти являлись традиционной обувью крестьян. По этой причине за словом закрепилось множество культурных коннотаций. Например, лапти ассоциируются с отсутствием культуры и необразованностью, простотой. Вместе с тем лапоть является одним из символов России. В португальском языке для обозначения схожего понятия есть слово alparca, которое, однако, не не имеет столь яркой культурной маркированности.

В русском культурном узусе изба ассоциируется с образом русской деревни. В разное время изба являлась как показателем зажиточной жизни, так и бедности, нищеты. Образ русской избы постоянно осмысливается и обыгрывается в русской художественной литературе, фольклоре, музыке и живописи. В настоящее время образ избы, ее классический интерьер активно используется для создания исторического или сказочного антуража туристических и развлекательных объектов. В переводе исследуемого романа португальский языке слову изба соответствует лексема casal, которая обозначает схожее понятие - ферму, маленький хутор, однако не имеет ярко выраженной национальной специфики, 
важной для культуры Бразилии.

3. Реалии, обозначающие тождественные или схожие понятия, но обладающие начионально-культурным содержанием, частично различающимся и частично совпадающим (P1 = P2 но K1 $\approx K 2)$.

Образы животных часто осмысливаются в художественной литературе и фольклоре. Различные повадки и облик животных приобретают переносное значение и находят отражение в языке. Однако как показывает исследование, носители двух языков могут характеризовать животных по-разному.

Медведь как в русском, так и в португальском языке ассоциируется с силой, опасностью, обладает буйным нравом. Однако если русские воспринимают медведя как существо с плохим слухом: «медведь на ухо наступил», а также плохого помощника: «медвежья услуга», то для носителей португальского языка медведь является объектом насмешек, имеет некрасивую внешность, а также характеризуется как фальшивый друг.

Заяц в обоих языках воспринимается как обманщик: для русских заяц - тот, кто ездит без билета, для португалоговорящих - меркантильный, неискренний гость. Кроме того, заяц в переносном значении используется для обозначения какого-либо дела, вопроса, проблемы, которая требует решения, что отражается во фразеологии обоих языков, например, «за двумя зайцами погонишься, ни одного не поймаешь» - за два дела возьмешься, ни одного не доведешь до конца; «levantar a lebre» - привлечь внимание к решению вопроса. Однако только в сознании русских заяц - существо робкое и трусливое: «трусливый как заяц».

Петух известен своим задиристым и драчливым нравом, как для русских, так и для носителей португальского языка. Помимо этого, в обеих культурах петух ассоциируется с высокомерием, например, «важный как петух»; «cantar de galo» - отдавать приказы, навязывать свою волю, а также считать себя исключительным. Однако только в русском культурном узусе петух ассоциируется с огнем, пожаром: «пустить красного петуха» - устроить пожар, имеет громкий некрасивый голос: «пустить nетуха» - издать фальшивый звук, а для носителей португальского языка петух обладает ветреным, легкомысленным характером: «galo doido» - легкомысленный человек. Кроме того, в Португалии петух является одним из национальных символов и в связи с национальной легендой характеризуется как справедливая птица.

Лошадь в обоих языках характеризуется как резвое, быстрое животное, требующее контроля: «aguentar os cavalos» - контролировать ситуацию; «придержать коней» - делать что-либо неспеша, не торопиться с вы- водами, а также представляющее ценность: «дареному коню в зубы не смотрят» — «a cavalo dado não se olham os dentes». Однако если русские воспринимают лошадь как сильное, здоровое - «лошадиное здоровье», мудрое существо - «старый конь борозды не испортит», которое много работает — «работать как лошадь», то в сознании носителей португальского языка лошадь - животное большое и глупое. В переносном значении cavalo назовут большого, грузного человека, а также того, кто не отличается сообразительностью.

Некоторые слова, обозначающие виды деятельности, могут по-разному восприниматься носителями русского и португальского языков.

Купец ассоциируется с хитростью и уловками в обеих культурах: для русских купец часто - обманщик, а в сознании бразильцев купец (mercador) может притворяться глухим, преследуя свои интересы: «fazer ouvido de mercador» - притворяться глухим, никого не слушать. Однако, например, в русской культуре купцом в переносном значении часто называют жениха без каких-либо негативных коннотаций. Кроме того, в русском фольклоре купец часто характеризуется как положительный персонаж.

Барин в русском языке и senhor (в значении феодал) в португальском характеризуются надменностью и пренебрежительным отношением к другим людям: «барские замашки» - высокомерное поведение; «ser senhor do seu nariz» - вести себя высокомерно. Однако другие коннотации слов барин и senhor различаются. В русской культуре барин воспринимается как праздный, ленивый человек: «жить барином» - жить в праздности и достатке, в то время как senhor ассоциируется со знанием дела, профессионализмом: «estar senhor de» - хорошо в чемлибо разбираться; независимостью: «ser senhor de si»быть независимым. Кроме того, в переносном значении Senhor используется в качестве обращения к Богу.

Слова, обозначающие национальные праздники, могут иметь понятийное сходство, но по-разному восприниматься носителями русского и португальского языков.

К таким словам можно отнести русскую Масленицу и бразильский карнавал. В сознании русских людей слово Масленица ассоциируется с весельем, праздником и входит в одну из народных пословиц: «Не все коту Масленииа, будет и Великий пост». Так говорят, желая напомнить кому-либо, что праздник и гуляния однажды кончаются. Carnaval в Бразилии также в первую очередь воспринимается как народный праздник: «fazer um carnaval»устраивать праздник, однако традиции проведения праздника значительно отличаются от русской Масленицы. Бразильский карнавал нередко сопровождается шумом, беспорядками и конфликтами, что находит отра- 
жение в языке и культуре: второе значение выражения «fazer um carnaval» - провоцировать конфликт.

Национальные русские блюда могут иметь аналоги в других культурах, что непосредственно отражается в языке, например, русские блины и panquecas в Бразилии и Португалии. Несмотря на понятийное сходство, слова, обозначающие эти блюда, по-разному воспринимаются носителями русского и португальского языков.

В древности у славян блины символизировали солнце и использовались как ритуальная пища - приносились в жертву богам, что нашло отражение в русской культуре. Блины и сейчас обязательно пекут на Масленицу и подают к столу на поминках. В русской культуре блины пекут быстро: «печь как блины» - делать что-либо быстро, а первый блин часто получается неудачным: «первый блин комом» - в начале дела бывают трудности. Этот образ понятен и носителям португальского языка: «a primeira panqueca é sempre grumosa». Однако только в русском языке слово блин используется в качестве эвфемизма и междометия в разговорной речи.

Слова, обозначающие традиционную русскую одежду, также могут иметь аналоги в других языках. Культурные коннотации этих слов могут быть частично схожими и частично различаться. Например, слова колпак и touca в переносном значении используются для характеристики простодушного человека, которого легко обхитрить. Однако слово колпак в русском языке также ассоциируется с защитой и покровительством — «жить под колпаком» - быть под защитой. Колпаком в разговорной речи часто называют подкаблучника. А слово touса в сознании носителей португальского языка ассоциируется со спиртными напитками.

Нередко историзмы приобретают в современном русском языке новые значения, входят в состав устойчивых сочетаний, которые вызывают у носителей языка ряд ассоциаций. Например, слово покои, которое ранее обозначало жилую часть деревенского дома, сегодня используется в таких выражениях как «мертвый покой», «nриемный покой» и ассоциируется с медициной. Аналог слова покоu - quarto в португальском языке также может ассоциироваться с медициной: «fazer quarto» - наблюдать за пациентом, готовить умерших к похоронам. Однако, помимо этого, quarto входит в состав фразеологизмов со значением хитрость, обман: «passar no quarto» - обмануть кого-либо; «dar um quarto aо diabo» - пойти на любые ухищрения для достижения своей цели.

4. Реалии, обозначающие аналогичные или тождественные понятия, но обладающие диаметрально противоположным или совершенно разным национально-культурным содержанием

$$
(\mathrm{P} 1=\mathrm{P} 2, \text { но } \mathrm{K} 1 \neq \mathrm{K} 2) \text {. }
$$

Оба слова non и padre используются для обозначения священника, служителя церкви, однако имеют противоположные коннотации в русском и португальском языках. В русском языке non - разговорное слово с пренебрежительным оттенком. Пренебрежительный характер слова связан с существованием попа - героя русской народной бытовой сказки, где он обычно сравнивается с другим персонажем - мужиком, который оказывается хитрей и умней попа. Слово поп используется только в разговорной речи, причем никогда не употребляется в функции обращения, а заменяется словами батюшка или святой отец. Португальское слово раdre в отличие от русского non используется в обращении к священнику, что считается проявлением большого почтения: «Santo Padre» - Святой отец. В переносном значении padre раньше употреблялось в обращении к отцу, что также считалось формой проявления уважения.

Оба слова хоровод и ciranda обозначают народные танцы, для которых характерны ритмичные круговые движения. Тем не менее слова имеют разные коннотации в русском и португальском языках. В национальнокультурном сознании русских хоровод - часть праздника, веселье: «С сумой ходить - не хороводы водить». В разговорной речи глагол хороводиться употребляется в переносном значении - иметь дело, обычно длительное, хлопотное с кем-либо, возиться. Другое значение этого глагола - водить компанию, знакомство, знаться, сожительствовать с кем-либо.

Для носителей португальского языка танец ciranda ассоциируется с последовательным, постепенным движением, что нашло отражение в языке. В разговорной речи слово ciranda часто употребляется в переносном значении - череда событий (например, A interminável ciranda dos dias.) Сам танец характеризуется быстрой сменой поз, громкой музыкой и смехом. По этой причине слово ciranda приобрело переносное значение шум, ажиотаж, беспорядок (например, Via-se no convés uma ciranda de cabeças coroadas.) Круговые, цикличные движения танца позже стали ассоциироваться с циркуляцией денег, слово ciranda стало экономическим термином и вошло в состав устойчивого выражения «сiranda financeira»— финансовый цикл.

Итак, проанализировав слова-реалии русского языка и их португальские соответствия в переводе романа «Евгений Онегин», мы можем сделать следующие выводы.

Национально-культурная семантика лексических единиц одного языка наиболее ярко проявляется и осознается при сопоставлении этих единиц с лексическими (или переводческими) соответствиями иного языка, которые принадлежат другой культуре. Являясь 
особой формой не только межъязыковой, но и межкультурной коммуникации, перевод отражает традиции, обычаи и мышление представителей обеих культур, которые в процессе перевода вступают во взаимодействие. В данной работе португальский перевод романа послужил инструментом лингвострановедческого исследования. Выбор того или иного лексического соответствия в переводе обусловлен не только языковыми факторами и целями переводчика, но и особенностями его национальной культуры. Следовательно, анализ средств культурной адаптации русских слов-реалий в переводе позволяет выявить то, как носители двух языков по-разному членят внеязыковую действительность и формируют собственную языковую картину мира. Исследование показало, что некоторые культурные коннотации слов совпадают в основных, существенных моментах. Однако две национальные культуры никогда не совпадают полностью.

\section{ЛИТЕРАТУРА}

1. Верещагин Е.М., Горожанкина Л.В. Принцип сопоставления двух культур и его реализация в страноведческом пособии по разговорной практике. РЯ3Р. - 1983. - № 2. - С. 24-35.

2. Томахин Г.Д., Фомин В.Н. Проблематика сопоставительного лингвострановедения. — В кн.: Научные традиции и новые направления в преподавании русского языка и литературы. - М., 1986. - С. 23-54.

3. Потебня А.А. 0 связи некоторых представлений в языке. — Фил. зап. — Вып. 3. — Воронеж, 1958. — 431 с.

4. Верещагин Е.М., Костомаров В.Г. Лингвострановедческая теория слова. - М., 1980. — 431 с.

5. Верещагин Е.М. Костомаров В.Г. Язык и культура. — 4-е изд., перераб, и доп. — М.: Русский язык, 1990. — 456 с.

6. Томахин Г.Д. Теоретические основы лингвострановедения. На материале лексических американизмов английского языка. - Дис. д-ра филол. наук. - М., 1984. - 367 c.

7. Лингвострановедческий словарь «Россия» [Электронный ресурс]. — Режим доступа: https://ls.pushkininstitute.ru/Isslovar/

8. Michaelis Dicionário Brasileiro da Língua Portuguesa. [Электронный ресурс.] — Режим доступа: http://michaelis.uol.com.br/

( Данилова Василиса Андреевна (vasilisa.danilovatpp@mail.ru).

Журнал «Современная наука: актуальные проблемы теории и практики»

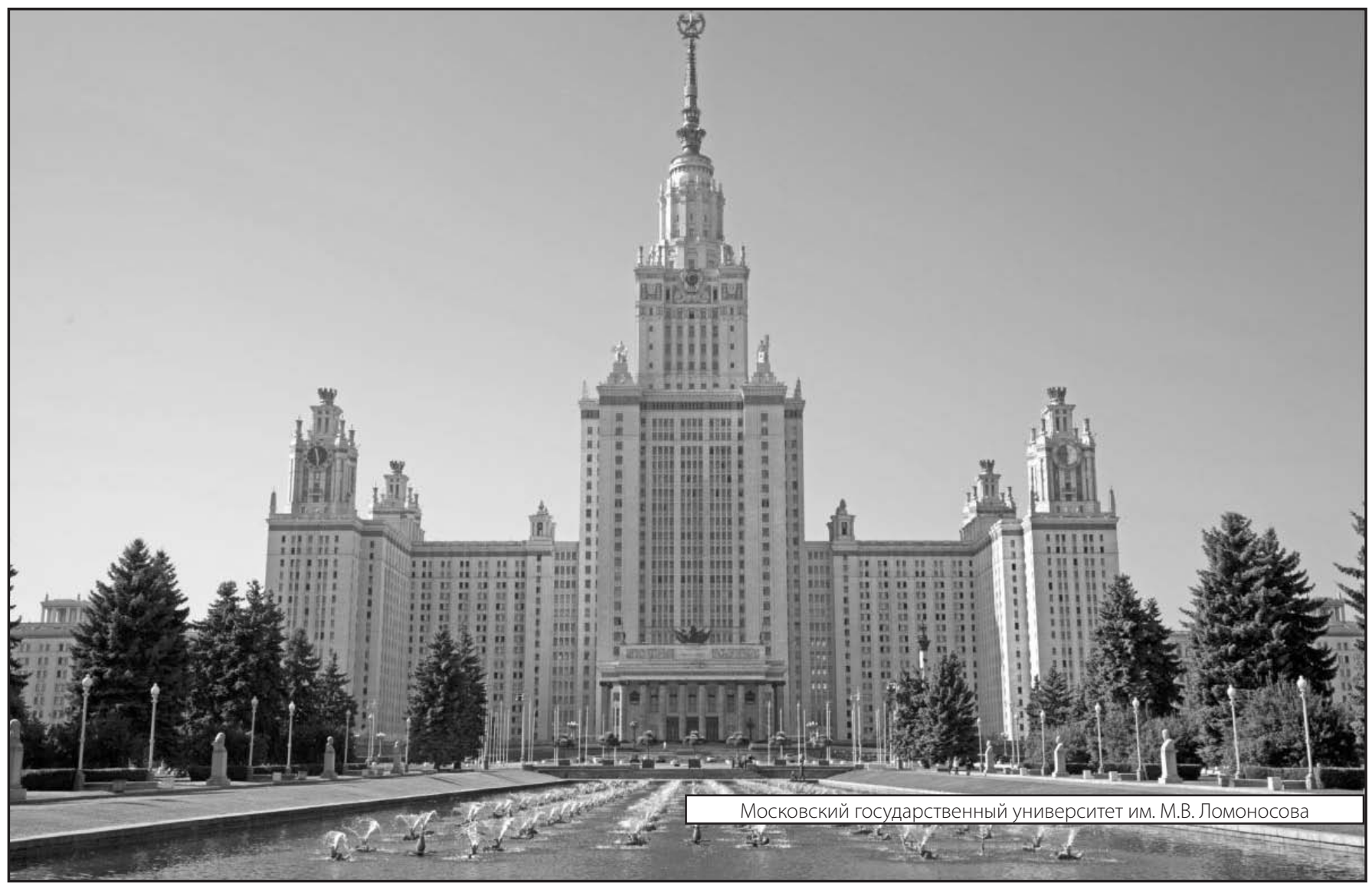

